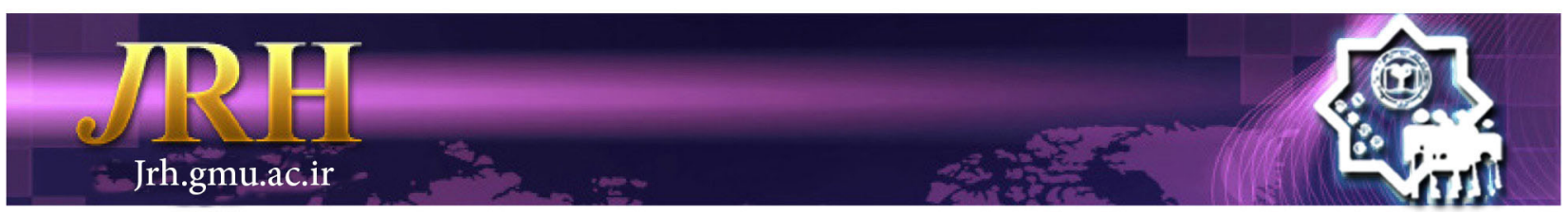

\title{
Attachment styles and emotional intelligence components: the predictors of health dimensions
}

Mahdi Taheri ${ }^{1}$, Jafar Hasani ${ }^{1}$, Hasan Rezayi Jamalooei ${ }^{1}$, Mansour Taheri $^{2}$

Journal of Research \& Health

Social Development \& Health Promotion Research Center

Vol. 9, No.1, Jan \& Feb 2019

Pages: $82-89$

DOI: 10.29252/jrh.9.1.82

Original Article

1. Department of Psychology, School of Psychology and Educational Sciences, Kharazmi University, Tehran, Iran

2. Department of Psychology, School of Psychology and Educational Sciences, Shahid Bahonar University, Kerman, Iran

Correspondence to: Mahdi Taheri, Department of Psychology, School of Psychology and Educational Sciences, Kharazmi University, Tehran, Iran

Email: taheri.20000@yahoo.com

Received: 17 Oct 2016

Accepted: 14 Jan 2017

How to cite this article: Taheri M, Hasani J, Rezayi Jamalooei H, Taheri M. Attachment styles and emotional intelligence components as the predictors of health dimensions. $J$ Research \& Health2019; 9(1): 82- 89 .

\begin{abstract}
Health, as one of the most important sources of comfort in life, is the complete physical, mental and social well-being, while there are dynamic mutual relationships among the three components. This study was aimed to investigate the role of attachment styles and emotional intelligence components in the prediction of health dimensions. The statistical population was consisted 160 parents who participated in the trainees' health assessment programs in Khalkhal city (Iran). Attachment styles questionnaire, emotional intelligence questionnaire and general health questionnaire were used to collect data. Results of the study indicated that avoidant and ambivalent attachment styles has significant relationship with depression dimension. The relationship between emotional intelligence and dimensions of depression, anxiety, physical symptoms and social performance was also significant. Multivariate regression analysis indicated that dependent and ambivalent attachments are predictors of depression/anxiety; secure attachment is a predictors of depression moreover, stress tolerance, social responsibility, empathy, self-esteem, optimism, self-actualization, interpersonal relations, problem solving, independence and assertiveness are predictors of depression, anxiety, physical symptoms and social performance. This study demonstrated that attachment styles and emotional intelligence components play important role in the prediction of health dimensions. Therefore they are applicable and effective in health related programs.
\end{abstract}

Keywords: Emotional Intelligence, Health, Parents

\section{Introduction}

Health, as one of the most important sources of comfort in life, is complete physical, mental and social well-being while there are dynamic mutual relationships between three components. Mental health is one of the determinants of health which was defined as a sense of well-being and self-effectiveness, self-reliance, competition capacity, intergenerational attachment and actualization of potential intellectual and emotional abilities [1]. The cause and treatment of all diseases is related to the body on the basis of the biological theory; however, based on the interactive theory, psychological factors can maintain and promote health and affect the timeline and treatment of illnesses and their etiology. Examples of psychological factors affecting health are coping styles, cognitive emotion regulation strategies, personality traits, attachment styles and emotional intelligence [2]. 
Attachment is a stable emotional bond between two people, in which one of the parties tries to maintain their affinity with the attachment subject and acts in such a way as to make sure of continuation of the relationship. Conducted researches on attachment have shown that the intimate relationship between mother and baby during the first years of life can impact on the nature of one's relations with others throughout life. Based on Bowlby's theory, the parent-child relationship is begun as a series of inborn signs that attracts the parent to the baby, creating an emotional bond over time which is strengthened by new cognitive and emotional abilities and warm and welcoming care. Bowlby believed that many of personality disorders are caused by the children's deprivation of maternal care or the instability in the child-attachment figure relationship. Any gap in the relationship between mother and baby can have many consequences for the child's personality development and prepare the ground for a variety of disorders in the future [3].

Studies in children classified the styles into secure, avoidant and ambivalent attachment styles [4], which are relatively stable from childhood to adulthood [5-7]. Researches in adults have shown those with secure attachment have a positive feeling of themselves and others, are socially self-reliable and more successful. Adults with avoidant attachment style consider themselves to be self-contained, deny vulnerability, claim no need to close relations with others and tend to avoid intimacy. Adults with ambivalent attachment style are less willing to have a positive view about them; they are often skeptical about their values and blame themselves for others' lack of responsibility. Furthermore, people with different attachment styles use totally different strategies to regulate feelings and process emotional information [8]. People with secure attachment style use the feeling regulation strategies that minimize stress and activate positive emotions. People with insecure attachment styles use strategies that insist on negative emotions that cause more stress. Different strategies cause people with secure attachment to cope with stressful situations better than insecure people and enjoy better mental health [9]. Research on the quality of attachment and consistency in the youth showed more depression, anxiety and stress were reported by the people with insecure attachment styles than those with secure attachment [10]. Another study in this regard indicated a significant association between attachment style and mental health [11]. Research has shown that attachment style has relationship with anxiety and depression [12], suicidal thoughts [13], psychological well-being [14] and the perceived physical and mental health [15]. Emotional intelligence which was defined as a set of non-cognitive skills, talents and capabilities that increase one's success in tackling environmental pressures and social connections [16] is another health predictor based on the theoretical foundations. Emotional intelligence was first suggested as a sort of social intelligence in 1990. Salovey and Mayer used a three-part model in which emotional intelligence was classified into three domains of appraisal of emotions, regulation of emotions and utilization of emotions to solve problems [17]. A four-dimension model was suggested including perception, appraisal and expression of emotions, emotional facilitation of thought, comprehension and analysis of emotional information, utilization of emotional knowledge and regulation of emotions [18].

Given that the ability to adaptively understanding and regulation of emotions in self and others is a fundamental component of emotional intelligence so more emotionally intelligent people are expected to be more compatible in the face of negative life experiences, enjoy a more extended social support network due to the correct understanding of emotions in others and empathy with them and are healthier [19]. In addition, emotional intelligence theorists believe that emotional intelligence is positively correlated with the ability to cope with high-risk situations and protect against stressors [20].

Recent researches showed a significant 
relationship between emotional intelligence and different indices of mental health [21], psychological well-being [22], quality of life [23], effective coping style [24] and life satisfaction [16]. Also meta-analytical results of 44 conducted studies in 7898 samples reported emotional intelligence to be a predictor of different health dimensions [25].

The present study was conducted to predict health dimensions based on attachment styles and emotional intelligence components because; health is a multidimensional concept which is affected by a variety of physical, psychological and social factors and makes it difficult for experts to identify effective factors in this area. The existing research has proved the important role of psychological constructs in the maintenance and promotion of health and the approximate stability of the components. Furthermore, no study has investigated these variables simultaneously and their results are inconsistent.

\section{Method}

This study is basic and correlational in terms of the goal and data collection method. The statistical population consists of 160 parents who participated in the trainees' health assessment programs upon school arrival in Khalkhal city, Iran in 2013. They were selected by convenience sampling. This study used the following measures for data collection:

1) General Health Questionnaire (GHQ): GHQ is one of the most well-known health appraisal tools which is available in different formats of $12,28,30$ and 60 items. This study used the 28item form [5]. It has four subscales of physical symptoms, anxiety, social performance and depression. Each subscale has seven items which are scored based on a four-point Likert scale of 0 to 3 ; a lower score indicates better health. The GHQ-28 was normalized in a group of 277 people in Nigeria and resulted in a reliability of 0.82 and validity of 0.85 . Another study used Cronbach's alpha to report the reliability coefficient of the whole scale and its subscale as $0.89,0.76,0.80,0.50$ and 0.85 , respectively [26].
2) Attachment styles questionnaire (ASQ): This study used 18-item Attachment styles questionnaire which is scored on a fivepoint Likert scale from zero (never) to five (definitely). It has three subscales of secure, avoidant and ambivalent attachment styles and the total score of individuals are calculated respectively [27]. For evaluating of questionnaire's reliability, the Cronbach's alpha of secure, avoidant and ambivalent attachment styles was reported as $0.84,0.75$ and 0.81 , respectively [27].

3) Emotional Intelligence Questionnaire (EIQ): This questionnaire has 117 items and 15 subscales and is scored on a five-point Likert scale (strongly agree, agree, agree to some extent, disagree and strongly disagree) [28]. The 15 subscales are emotional selfawareness, assertiveness, self-esteem, selfactualization, independence, empathy, social responsibility, interpersonal relationship, reality testing, flexibility, problem-solving, stress tolerance, impulse control, optimism and happiness [29]. Based on Bar-On's emotional intelligence model, the 15 subscales are assessed as following five dimensions: 1) The intrapersonal dimension including subscales of emotional self-awareness, assertiveness, selfesteem, self-actualization and independence; 2) The interpersonal dimension including subscales of empathy, interpersonal relationships and social responsibility; 3 ) The adaptability dimension including problemsolving skills, reality testing and flexibility; 4) the stress management dimension including stress tolerance and impulse control and 5) the general mood dimension including a feeling of happiness and optimism [30].

Reliability of the main version of the scale was reported as 0.76 to 0.93 in various studies [31]. This scale was normalized in the Iranian culture for university students. After conducting the factor analysis and the examination of internal consistency of items, the items were reduced to 90 . However, the factor construct of the questionnaire was maintained. Moreover, the test reliability was reported by the calculation of Cronbach's alpha for boy students, girl 
students and the whole population as $0.74,0.68$ and 0.93 , respectively [32].

\section{Results}

Table 1 shows the mean, standard deviation and correlation coefficients of health dimensions, attachment styles and emotional intelligence subscales which indicate significant relationship between avoidant and ambivalent attachment styles with the subscale of depression. Subscales of emotional intelligence including happiness, stress tolerance, self-actualization, emotional self-awareness, reality testing, self-esteem and impulse control have significant relationship with all of health subscales; interpersonal relations and optimism are significantly related to anxiety, social performance and depression; assertiveness is significantly related to social performance and depression while empathy has a significant relation with social performance.

Table 1 Mean and standard deviation of health, emotional intelligence and attachment subscales and correlation coefficients between predictors and health subscales

\begin{tabular}{|c|c|c|c|c|c|c|c|}
\hline \multirow[b]{2}{*}{ Scale } & \multirow[b]{2}{*}{ Subscales } & \multirow[b]{2}{*}{ Mean } & \multirow{2}{*}{$\begin{array}{l}\text { Standard } \\
\text { deviation }\end{array}$} & \multicolumn{4}{|c|}{ Health } \\
\hline & & & & $\begin{array}{l}\text { Physical } \\
\text { symptoms }\end{array}$ & Anxiety & $\begin{array}{c}\text { Social } \\
\text { performance }\end{array}$ & Depression \\
\hline \multirow{3}{*}{ Attachment } & Secure attachment & 19.54 & 6.44 & 0.07 & 0.04 & 0.11 & 0.08 \\
\hline & Avoidant attachment & 19.57 & 2.72 & 008 & -0.07 & -0.04 & $-0.17 *$ \\
\hline & Ambivalent attachment & 19.32 & 4.76 & 0.08 & -0.10 & 0.02 & $0.29 * *$ \\
\hline \multirow{16}{*}{$\begin{array}{l}\text { Emotional } \\
\text { Intelligence }\end{array}$} & Problem solving & 23.25 & 2.94 & 0.09 & 0.16 & 0.08 & 0.07 \\
\hline & Happiness & 23.10 & 4.43 & $-0.19 *$ & $-0.30 * *$ & $-0.29 * *$ & $-0.35 * *$ \\
\hline & Independence & 19.86 & 4.20 & 0.07 & -0.04 & -0.09 & $-0.23 * *$ \\
\hline & Stress tolerance & 19.59 & 3.84 & $-0.38 * *$ & $-0.51 * *$ & $-0.49 * *$ & $-0.54 * *$ \\
\hline & Self -actualization & 22.00 & 4.13 & $-0.20 *$ & $-0.20^{*}$ & $-0.22 * *$ & $-0.33 * *$ \\
\hline & Emotional self-awareness & 20.83 & 2.91 & $-0.17 *$ & $-0.18^{*}$ & $-0.20 *$ & $-0.18^{*}$ \\
\hline & Reality testing & 18.51 & 3.76 & $-0.17 *$ & $-0.22 * *$ & $-0.33 * *$ & $-0.38 * *$ \\
\hline & Interpersonal relations & 24.33 & 3.69 & -0.11 & $-0.18^{*}$ & $-0.36^{* *}$ & $-0.17^{*}$ \\
\hline & Optimism & 22.68 & 3.58 & -0.14 & $-0.23 * *$ & $-0.24 * *$ & $-0.21 * *$ \\
\hline & Self -esteem & 23.25 & 3.09 & $-0.26^{* *}$ & $-0.25^{* *}$ & $-0.41 * *$ & $-0.28 * *$ \\
\hline & Impulse control & 17.84 & 4.77 & $-0.17 *$ & $-0.20 *$ & $-0.28 * *$ & $-0.37 * *$ \\
\hline & Flexibility & 18.35 & 2.63 & -0.12 & -0.01 & -0.07 & -0.09 \\
\hline & Social responsibility & 24.94 & 3.68 & 0.02 & 0.06 & -0.04 & -0.09 \\
\hline & Empathy & 23.46 & 3.71 & -0.11 & 0.07 & $-0.23 * *$ & -0.04 \\
\hline & Assertiveness & 17.55 & 3.85 & 0.06 & -0.07 & $-0.24 * *$ & $-0.26 * *$ \\
\hline & $\begin{array}{l}\text { Overall score of emotional } \\
\text { intelligence }\end{array}$ & 319.53 & 36.01 & $-0.19 *$ & $-0.24 * *$ & $-0.36 * *$ & $-0.37 * *$ \\
\hline \multirow{4}{*}{ Health } & Physical symptoms & 10.42 & 3.01 & & & & \\
\hline & Anxiety & 11.82 & 3.47 & & & & \\
\hline & Physical performance & 11.75 & 2.61 & & & & \\
\hline & Depression & 10.72 & 2.57 & & & & \\
\hline
\end{tabular}

${ }^{*} \mathrm{p}<0.05, * * \mathrm{p}<0.01$

The stepwise multivariate regression analysis was used to investigate the role of attachment styles and emotional intelligence subscales in the prediction of health dimension (Table 2). The results indicate that attachment styles and emotional intelligence subscales are significant predictors for all dimensions of health and explain $45 \%$ and $42 \%$ of the variance of the anxiety and depression subscales respectively; they also explain $49 \%$ and $31 \%$ of the variance of social performance disorder and physical symptoms. Furthermore, ambivalent and avoidant attachment styles are regarded as predictors of anxiety and depression while secure attachment style is a predictors of depression. Emotional intelligence subscales predict health dimension; stress tolerance and social responsibility are predictors of all 
health dimensions; empathy predicts anxiety and social performance, self-esteem is a predictor of social performance and physical symptoms; assertiveness predicts depression and social performance, while self-actualization and problem solving are predictors of social performance; independence predicts physical symptoms and interpersonal relations is a predictor of social performance and physical symptoms.

Table 2 Results of the regression analysis of attachment styles and emotional intelligence subscales as predictors of health dimensions

\begin{tabular}{|c|c|c|c|c|c|c|}
\hline Standard variable & Predictor & Beta & $\mathrm{T}$ & $\mathrm{R}$ & $\mathrm{R}^{2}$ & $\mathrm{~F}$ \\
\hline \multirow{5}{*}{ Anxiety } & Stress tolerance & -0.72 & $-10.66 * * *$ & \multirow{5}{*}{0.67} & \multirow{5}{*}{0.45} & \multirow{5}{*}{$24.88 * * *$} \\
\hline & Social responsibility & 0.53 & $6.45 * * *$ & & & \\
\hline & Empathy & -0.26 & $-3.46 * * *$ & & & \\
\hline & Ambivalent attachment & -0.19 & $-3.11 * *$ & & & \\
\hline & Avoidant attachment & -0.13 & $-2.08^{*}$ & & & \\
\hline \multirow{6}{*}{ Depression } & Stress tolerance & -0.57 & $-7.95 * * *$ & \multirow{6}{*}{0.65} & \multirow{6}{*}{0.42} & \multirow{6}{*}{$18.72 * * *$} \\
\hline & Social responsibility & 0.27 & $3.75 * * *$ & & & \\
\hline & Ambivalent attachment & 0.21 & $3.27 * * *$ & & & \\
\hline & Avoidant attachment & -0.21 & $-3.29 * * *$ & & & \\
\hline & Secure attachment & -0.16 & $-2.49 * *$ & & & \\
\hline & Assertiveness & -0.13 & $-1.98 *$ & & & \\
\hline \multirow{8}{*}{ Social performance } & Stress tolerance & -0.58 & $-6.45 * * *$ & \multirow{8}{*}{0.70} & \multirow{8}{*}{0.49} & \multirow{8}{*}{$18.03 * * *$} \\
\hline & Social responsibility & 0.40 & $4.46^{* * *}$ & & & \\
\hline & empathy & -0.29 & $-3.17 * *$ & & & \\
\hline & Self-actualization & 0.25 & $2.80 * *$ & & & \\
\hline & Interpersonal relations & -0.24 & $-3.03 * *$ & & & \\
\hline & Self-esteem & -0.20 & $-2.36 * *$ & & & \\
\hline & Problem solving & 0.16 & $-2.01 *$ & & & \\
\hline & Assertiveness & -0.13 & $-2.10 *$ & & & \\
\hline \multirow{5}{*}{ Physical symptoms } & Stress tolerance & -0.55 & $-6.48 * * *$ & \multirow{5}{*}{0.56} & \multirow{5}{*}{0.31} & \multirow{5}{*}{$13.90 * * *$} \\
\hline & Self-esteem & -0.37 & $-4.02 * * *$ & & & \\
\hline & Independence & 0.35 & 4.20 & & & \\
\hline & Social responsibility & 0.23 & $2.52 * *$ & & & \\
\hline & Interpersonal relations & 0.18 & $1.99 * *$ & & & \\
\hline
\end{tabular}

${ }^{*} \mathrm{p}<0.05, * * \mathrm{p}<0.01, * * * \mathrm{p}<0.001$

\section{Discussion}

The present study was conducted to investigate attachment styles and emotional intelligence subscales as the predictors of health dimensions. Results indicated that the overall score of emotional intelligence has a significantly positive relationship with health dimensions and the more emotionally intelligent people have the better health. This finding consistent with [21-23,25] which reported a positive relationship between emotional intelligence and health. Emotional intelligence theorists believed that emotional intelligence is positively correlated with the ability to cope with stressful situations and it acts as a protective agent against stressors and promotes health [20]. Researches have shown that people with higher emotional intelligence enjoy more happiness, vitality, liveliness and independence, have better performance, are more robust against difficulties because of their optimism and hope to the future and progress more in their life. It also identifies them as creative and thoughtful people who enjoy overcoming problems and challenging situations are goal oriented and persistent during tasks [32]. Accordingly, people with higher emotional intelligence than ordinary ones show more adaptive responses to disastrous and negative events directly face different events and problems in life and can adapt to problems and challenges better and control their emotions more effectively. Different dimensions of their health are promoted as a result of the mentioned factors. Based on the results, avoidant and ambivalent attachment styles have a significant and positive relationship with the dimension of depression; people with the two attachment 
styles exhibit have symptoms of depression and have less health. These findings are compatible with the results of $[10,12]$ that reported a positive relationship between insecure attachment style and depression. They are also consistent with $[11,14,15,33]$ that indicated a negative relationship between insecure attachment styles and health. In is worth to mention that people with avoidant or ambivalent attachment styles use more negative emotional regulation strategies and fail to regulate emotions. On the other hand, people with secure attachment styles use emotion regulation strategies that minimize stress and activate positive emotions. The use of inefficient strategies by people with insecure attachment reduces their strength to cope with stressful conditions and make them more vulnerable [9].

This study found ambivalent and avoidant attachment styles as predictors of anxiety and depression. It also found secure attachment style as a predictor of depression. Moreover, emotional intelligence subscales such as stress tolerance and social responsibility are predictors of all dimensions of health while empathy is predictor of anxiety and social performance. Self-esteem and assertiveness are predictors of social performance/physical symptoms and depression/social performance respectively. Selfactualization/problem solving, independence and interpersonal relations are predictors of social performance, physical symptoms and social performance/physical symptoms respectively. Today, man's life is facing to numerous complex types of stress and health maintenance requires coping with them and finding a suitable solution. The ability to cope with pressures predisposes the maintenance of one's mental, physical and social health while failing to do this paves the way for many mental and physical illnesses. Experts define mental health as a subjective status of emotional health with no anxiety, the ability to make constructive relations, cope with demands and life stressors and they believe that emotional intelligence plays major role in this regard [34]. Inefficient emotion regulation strategies of people with insecure attachment styles make them less able to cope with stressful situations which are associated with an increased anxiety in the short term and a reduced sense of personal efficacy and increased depression in the long term [8]. Research has shown that emotional intelligence is positively related to the coping style [24]. Furthermore, high emotional intelligence is mostly accompanied with higher satisfaction with life [16].

Among the dimensions of health, social functioning was predicted with the highest number of components of emotional intelligence. Research has shown that affiliative humor style which is mostly used by people with higher emotional intelligence predisposes them to higher social performance through decreasing interpersonal conflicts and facilitating the establishment and maintenance of relations [35]. In addition, because of the role of emotional intelligence in understanding others' emotions as well as adaptive regulation and inhibiting one's emotions, it is expected that emotionally intelligent people are more skillful at true understanding and empathy with others' emotions have an extended social network and then better social performance. Such as other studies one of the limitations of the present study is the limitation of generalizing its results to a particular population. Therefore it's suggested that the results be generalized cautiously.

\section{Conclusion}

This study has found that emotional intelligence and attachment styles are effective on health. Healthcare professionals are recommended to take necessary measures to promote these components in the society. So these components are relatively stable over time; their promotion will lead to changes in people's psychologically and socially health.

\section{Acknowledgements}

We thank all the people and authorities who participated in this study or helped us in this research.

\section{Contribution}

Study design: JH, MT, HRJ 
Data collection and analysis: MT, HRJ, MT Manuscript preparation: JH, MT, HRJ, MT

\section{Conflict of Interest}

"The author declares that they have no competing interests."

\section{Funding}

The author (s) received no financial support for the research, authorship and/or publication of this article.

\section{References}

1- World health organization. The world health report. Geneva: Health system; 2001.

2- Ogden J. Health psychology. England: Open university press; 2012.

3- Bowlby J. The making and breaking of affection bonds. London: Psychology press; 1979.

4- Ainsworth MD, Wittig BA. Attachment and exploratory behavior of one-year-olds in a strange situation. In: Foss BM, ed. Determinants of infant behavior. London: Methuen; 1969. pp: 113-36.

5- Goldberg S. Recent developments in attachment theory and research. Can J Psychiatry1991; 36(6): 393-400.

6- Noftle EE, Shaver PR. Attachment dimensions and the big five personality traits: associations and comparative ability to predict relationship quality. $J$ Res Personal2006; 40: 179-208.

7- Chris Fraley R. Attachment stability from infancy to adulthood: meta-analysis and dynamic modeling of developmental mechanisms. Pers Soc Psychol Rev2002; 6(2): 123-51.

8- Shaver PR, Schachner DA, Mikulincer M. Attachment style, excessive reassurance seeking, relationship processes, and depression. Pers Soc Psychol Bull2005; 3(1): 343-59.

9- Linley PA, Joseph S. Positive change following trauma and adversity: areview. J Traum Stress2004; 17(8): 11-21. 10- Vivona JM. Parental attachment styles of late adolescents: qualities of attachment relationships and consequences for adjustment. J Couns Psychol2000; 47(3): 316-29.

11- Neria Y, Guttmann-Steinmetz S, Koenen K, Levinovsky L, Zakin G. Do attachment and hardiness relate to each other and to mental health in real-life stress? J Soc Pers Relat2001; 18: 844-60.

12- Kadir A, Bayah N. Insecure attachment style as a vulnerability factor for depression: Recent findings in a community-based study of Malay single and married mothers. Psychiatry Res2013; 210(3): 919-24.

13- Davaji RBO, Valizadeh S, Nikamal M. The relationship between attachment styles and suicide ideation: the study of Turkmen students, Iran. Procedia Soc Behav Sci2010; 5: 1190-4.

14- Ozturk A, Tansu Mutlu T. The relationship between attachment style, subjective well-being, happiness and social anxiety among university students'. Procedia Soc Behav Sci2010; 9: 1772-6

15- Chraif M, Mihai Anitei M. Overload learning, attachment and coping styles predictors of mental and physical health of teenage high school students in Romania. Procedia Soc Behav Sci2012; 69: 1842-6.

16- Whitney C. Social supports among college students and measures of alcohol use, perceived stress, satisfaction with life, emotional intelligence and coping. Journal Student Wellb2010; 4(1): 49-67.

17- Salovey P, Mayer JD. Emotional intelligence. Imagination, cognition, and personality. $J E d u c$ Psychol1990; 9: 185-211.

18-Mayer JD, Salovey P. What is emotional intelligence? In Salovay P, Sluyter D, eds. Emotional development and emotional intelligence: implication for educator. New York: Psychology press; 1997. pp: 113-6.

19- Maloff JM, Schutte NS. Games to enhance social and emotional skills. USA, Springfield, il: Charles Thomas; 1998.

20- Salovey P, Bedell BT, Detweiller JB, Mayer GD. Coping intelligently: emotional intelligence and the coping process. In Snyder CR, Lopez J, eds. Coping: The psychology of what works. New York: Oxford University press; 1999. pp:141-64.

21- Zeidner M, Matthews G, Roberts RD. The emotional intelligence, health, and well-being nexus: What have we learned and what have we missed? Appl Psychol: Health Well-Being2012; 4: 1-30.

22- James1 C, Bore1 M, Zito S. Emotional intelligence and personality as predictors of psychological wellbeing. J Psychoeduc Assess2012; 30(4): 425-38.

23- Yalcin BM, Karahan TF, Ozcelik M, Igde FA. The Effects of an emotional intelligence program on the quality of life and well-being of patients with type 2 diabetes mellitus. Diabetes Educ2008; 34: 1013-24.

24- Campbell A, Ntobedzi A. Emotional intelligence, coping and psychological distress: a partial least squares approach to developing a predictive model. Electron J Appl Psychol2007; 3: 39-54.

25- Schutte NS, Malouff JM, Thoresteinson EB, Bhullar N, Rooke SE. A meta-analytic investigation of the relationship between emotional intelligence andhealth. Pers Individ Dif2007;42(6): 921-33.

26- Mollazadeh J, Ashoori A. Efficacy of CBT in preventing relapse and improving the mental health of addicts. Daneshvar Raftar2009; 16: 1-12.

27- Hosseini SMD, Mollazadeh J, Kazerouni PA, Lari MA. The relationship between attachment styles and 
religios coping styles with mental health among HIV patients. Journal of Fundamentals of Mental Health2012; 1(53): 6-15.

28- Bar-On R, Parker JDA. The bar-on emotional quotient inventory: youth version (EQ-i: YV) technical manual. Toronto, Canada: Multi-Health systems; 2000.

29- Bar-On R, Handley R. The Bar -On EQ-360. Toronto, Canada: Multi-Health systems; 2003.

30- Bar-On R, Brown JM, Kirkcaldy BD, Thome EP. Emotional expression and implications foroccupational stress: An application of the Emotional Quotient Inventory (EQ-i). J Pers Individ Dif2000; 28: 1107-18.

31- Markey MA, Vander Wal JS. The role of emotional intelligence and negative affect in bulimic symptomatology. Compr Psychiatry2007; 5: 458-64. 32-ZareanM,PooraminA,BakhshipoorA.Therelationship between emotional intelligenceandproblemsolving styles with publichealth. Iranian Journal of Psychiatry and Clinical Psychology2006; 13(2): 166-73.

33- Delavarpour MA, Lattifian M. An investigation into the relationship between attachment style and mental health by the mediating role of emotional creativity. Advances in Cognitive Science2012; 14(2): 45-62.

34- Corsini RJ. The dictionary of psychology. London: Brunner / Mazel publishers; 1999.

35- Hampes WP. Humor and shyness: The relation between humor styles and shyness. Int J Humor Res2006;19(2):179-187.

Copyright $(2016$ ASP Ins. This open-access article is published under the terms of the Creative Commons Attribution-NonCommercial 4.0 International License which permits Share (copy and redistribute the material in any medium or format) and Adapt (remix, transform, and build upon the material) under the Attribution-NonCommercial terms. 